\title{
Good health requires a healthy mouth: improving the oral health of Canada's seniors
}

\author{
Diane Kelsall MD MEd, John O'Keefe BDentSc MDentSc MBA
}

$\mathrm{P}$ icture this scenario. A 74-year-old patient presents with an infected wound the size of the palm of her hand. The doctor tells the patient that there is no health coverage in her province for the care of this type of infected wound in seniors. She will have to pay out of pocket. On a tight budget, the patient leaves without treatment.

Sound implausible? It shouldn't. The patient has periodontitis rather than a skin infection. Although the periodontal surface area of the mouth is substantial, and periodontal infection is associated with systemic diseases such as coronary artery disease, stroke and aspiration pneumonia, ${ }^{1-3}$ most seniors in Canada do not have coverage for dental care, apart from specific oral surgery procedures that are performed in hospital. ${ }^{4}$ This lack of coverage has serious health implications for older Canadians, which puts this vulnerable group at higher risk for both dental and systemic disease.

There is a growing body of evidence showing the association between oral disease and systemic disease, but this relationship has not been completely elucidated. ${ }^{1,3}$ Although periodontal disease has been linked with diabetes, rheumatoid arthritis and obesity, among other conditions, the strongest evidence for a relationship is found with cardiovascular disease. ${ }^{1,3}$ The role of chronic inflammation in atherogenesis is well known and may explain the association. Direct effects of infection may also play a role. ${ }^{3}$

\section{About one in six seniors decline recommended dental treatment because of cost.}

Many seniors have poor oral health, older age being the strongest determinant of periodontal disease. The Canadian Health Measures Survey reported that one in six seniors aged 60 to 79 years in the community had untreated dental caries. ${ }^{5}$ More than half had periodontal disease, with $15 \%$ having evidence of severe disease. About one in five had no remaining teeth.

Although most seniors claim to brush and floss as regularly as younger people, ${ }^{5}$ several factors contribute to an increased risk of poor oral health in this age group. Over time, hypofunction of the salivary glands can occur which, along with some medications and chronic diseases, reduces the amount of saliva production and increases the bacterial load in the mouth. ${ }^{2}$ Gingival attachment loosens. Older patients may have mechanical difficulty brushing and flossing. Chronic diseases and poor nutrition contribute to reduced immunity against infection, leading to periodontal disease. ${ }^{2}$ A vicious cycle of poor dentition, malnutrition and increased comorbidities can result. ${ }^{2}$ Even in seniors without teeth, denture stomatitis or food avoidance may occur, compounding systemic concerns. ${ }^{2}$

In Canada, only Alberta and Yukon Territories provide financial assistance for dental care to people over the age of 65 years. ${ }^{4}$ On retirement, most lose their dental benefits and must either pay directly for dental services or purchase a dental care plan from an insurer. The Canadian Health Measures Survey showed that more than half of seniors in the community did not have any dental coverage, and about $39 \%$ were covered by private insurers. ${ }^{5}$ More than 1 in 10 older people reported avoiding dentists, and about 16\% declined recommended dental treatment because of the expense. Severe periodontal disease was most prevalent in those without health insurance. In fact, a lack of health insurance was the only factor that appeared to influence the prevalence of severe disease.

The consequences of poor oral health extend far beyond the mouth. With our aging population, the burden of illness associated with oral and related diseases can increase health care and socioeconomic expenditures across the system. ${ }^{4} \mathrm{~A}$ lack of dental coverage, however, is an impediment to maintaining good oral health in older Canadians. ${ }^{5}$ Determining how best to ensure that this vulnerable group has access to dental care will require discussion among interested stakeholders, a process recently initiated by the Canadian Dental Association. We hope this dialogue will create a roadmap that will lead to tangible positive oral health outcomes for seniors.

\section{References \\ 1. Galgut PN. Periodontal disease and poor health outcomes. BMJ 2010;340:c2735. \\ 2. Yao CS, MacEntee MI. Inequity in oral health care for elderly Canadians: Part 1. Oral health status. J Can Dent Assoc 2014;79:d114. \\ 3. Ford PJ, Raphael SL, Cullinan MP, et al. Why should a doctor be interested in oral disease? Expert Rev Cardiovasc Ther 2010;8:1483-93. \\ 4. Yao CS, MacEntee MI. Inequity in oral health care for elderly Canadians: Part 2. Causes and ethical considerations. J Can Dent Assoc 2014;80:e10. \\ 5. Report on the findings of the Oral Health Component of the Canadian Health Measures Survey 2007-2009. Ottawa: Health Canada; 2010. Available: www .fptdwg.ca/assets/PDF/CHMS/CHMS-E-tech.pdf (accessed 2014 July 23).}

Competing interests: For Diane Kelsall's competing interests, www.cmaj. ca/site/misc/cmaj_staff.xhtml. None declared for John O'Keefe.

Affiliations: Diane Kelsall is Deputy Editor, CMAJ, and John O'Keefe is Director, Knowledge Networks, Canadian Dental Association and Editor, Journal of the Canadian Dental Association, Ottawa, Ont.

Correspondence to: $C M A J$ editor,pubs@cmaj.ca

CMAJ 2014. DOI:10.1503/cmaj.140975 